\title{
Repair of Postoperative Cervical Pseudomeningocele with the Use of Bone Morphogenetic Protein
}

\author{
Dejan Slavnic $^{1}$, Robert Mccabe ${ }^{1}$, Doris Tong ${ }^{1}$, Teck M. Soo ${ }^{1}$ \\ 1. Neurosurgery, Ascension Providence Hospital, Michigan State University, College of Human Medicine, Southfield, \\ USA
}

Corresponding author: Dejan Slavnic, dejanslavnic82@gmail.com

\begin{abstract}
Recurrent cerebrospinal fluid (CSF) leak carries significant morbidity and mortality. A 25-year-old Caucasian male developed a symptomatic pseudomeningocele eight days after surgical resection of a cervical schwannoma. With no improvement after lumbar drain placement, the dural sleeve defect over the left C3 nerve root was repaired with suturable DuraGen ${ }^{\circledR}$ (Integra LifeSciences, Plainsboro, NJ, USA). Muscle and fat graft were then laid over the repair site and covered by Tisseel ${ }^{\circledR}$ (Baxter Healthcare, Deerfield, IL, USA). Recombinant human bone morphogenetic protein-2 (rhBMP-2) was applied via extra-small sponge laid over the graft. At 15-month clinical and 16-month radiographic follow-up, the patient had complete resolution of symptoms without any evidence of infection, ectopic bone formation, excessive inflammation, neoplasm, or recurrent CSF leak. This case demonstrates the successful use of BMP in the treatment of recurrent symptomatic cervical pseudomeningocele after tumor resection. We believe that the proinflammatory effects of rhBMP-2 lead to early scarring of dural defect and resolution of CSF leak.
\end{abstract}

Categories: Neurosurgery

Keywords: cervical spine, csf leak, pseudomeningocele, bone morphogenetic protein, bmp

\section{Introduction}

Cerebrospinal fluid (CSF) leak after spinal surgery may lead to significant morbidity including CSF fistulas, meningitis, brain abscess, intracranial hemorrhage, and neurologic deficits $[1,2]$. The incidence of CSF leak varies depending on the procedure performed, but it is generally higher with open spine approaches [3]. In instances where the dura is violated without injury to the arachnoid membrane, a true meningocele lined with the arachnoid membrane may develop. However, in dural-arachnoid tears, such as during intradural tumor resection, extravasation of CSF outside of the thecal sac will inadvertently form a pseudomeningocele, a CSF pseudocyst lined by fibrous tissue $[4,5]$.

Received 05/29/2019 Review began 06/24/2019 Review ended 07/03/2019 Published 07/22/2019

\section{○ Copyright 2019} Slavnic et al. This is an open access article distributed under the terms of the Creative Commons Attribution License CC-BY 3.0., which permits unrestricted use, distribution, and reproduction in any medium, provided the original author and source are credited.
We present a case of recurrent CSF leak and a symptomatic pseudomeningocele formation after resection of a cervical schwannoma in a 25-year-old male who later underwent surgical repair with the use of bone morphogenetic protein (BMP). BMPs have been used successfully to treat recurrent CSF leak after transsphenoidal surgery [6]. In our institution, we have effectively applied recombinant human bone morphogenetic protein-2 (rhBMP-2) for the repair of persistent CSF leak secondary to encephalocele. BMPs are signaling molecules that belong to a superfamily of proteins known as transforming growth factor$\beta$ (TGF- $\beta$ ) that are mostly involved in osteogenesis $[7,8]$. When used in high quantities BMPs were associated with complications such as ectopic bone growth, osteolysis, and systemic neoplasm [9]. We sought to demonstrate that BMPs could be used in the repair of recurrent CSF leak and pseudomeningocele without long-term complications.

\section{Case Presentation}

A 25-year-old male without significant past medical history presented to the neurosurgery clinic with worsening left shoulder and neck pain. Magnetic resonance imaging (MRI) revealed a 2.6 x $1.1 \mathrm{~cm}$ intradural extramedullary mass within the left C2-3 neural foramen consistent with schwannoma. The patient underwent left C2-3 hemilaminectomy with complete resection of the tumor. The $2 \mathrm{x} 1 \mathrm{~cm}$ dural defect was repaired in a water-tight fashion with suturable collagen matrix (DuraGen ${ }^{\circledR}$, Integra LifeSciences, Plainsboro, NJ, USA) and covered by fibrin sealant (Tisseel ${ }^{\circledR}$, Baxter Healthcare, Deerfield, IL, USA). There were no complications, and he was sent home four days later. On postoperative day eight, the patient returned to the emergency room with symptoms of nausea, vomiting, headache, and photophobia that worsened when he was upright. MRI showed a large pseudomeningocele at the surgical site (Figure 1) for which lumbar drain was placed. The patient's symptoms returned after the drain was removed five days later. Therefore, the decision was made to proceed with surgical exploration and repair. 


\section{Cureus}

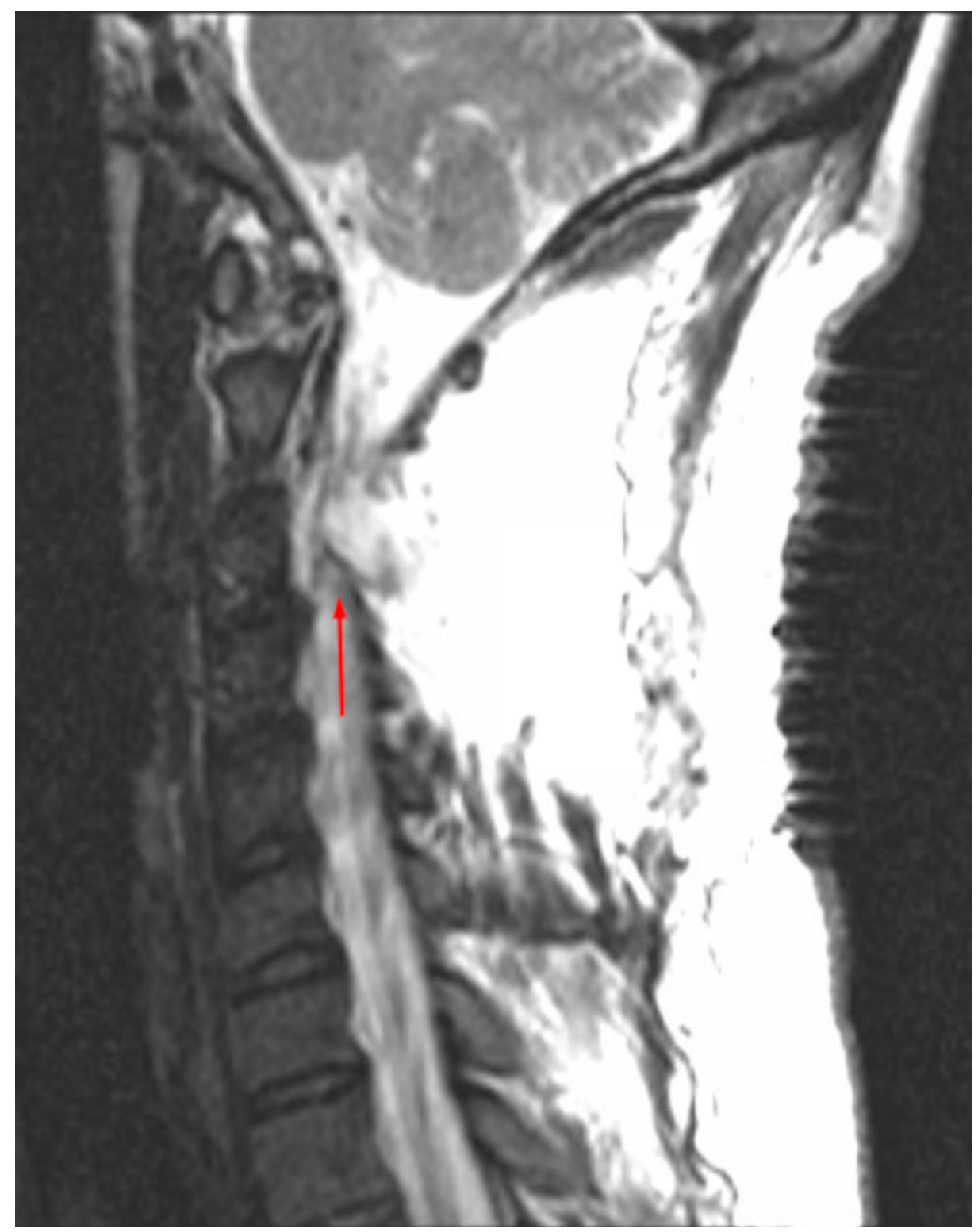

FIGURE 1: Cervical spine sagittal MRI without contrast demonstrating a large pseudomeningocele within the surgical site prior to dural repair with BMP

MRI (Magnetic Resonance Imaging), BMP (Bone Morphogenetic Protein)

A lumbar drain was inserted at the beginning of surgery. The posterior cervical incision was opened and explored. The $2 \times 1 \mathrm{~cm}$ dural defect was localized, and suturable DuraGen ${ }^{\circledR}$ was used to repair the defect completely. A piece of fascia and fat graft were laid over the dura and covered by Tisseel ${ }^{\circledR}$. The $2 \times 2 \mathrm{~cm}$ absorbable sponge from the extra-small BMP kit was soaked with $1.4 \mathrm{cc}$ rhBMP-2 and laid over the top. The suction drain (Hemovac ${ }^{\circledR}$, Zimmer Biomet, Warsaw, IN, USA) was inserted, and the wound closed in a standard anatomical layer fashion without any complications.

The lumbar drain remained in place and was open to drain for five days. The patient was discharged home on postoperative day six. He was followed clinically for 15 months after surgery. The MRI at 16 months postsurgery showed no evidence of recurrent tumor, CSF leak, infection, extraneous bony growth, excessive inflammation, or neoplasm (Figure 2). 


\section{Cureus}



FIGURE 2: Cervical spine sagittal MRI without contrast showing a nearcomplete resolution of the pseudomeningocele after dural repair with BMP

MRI (Magnetic Resonance Imaging), BMP (Bone Morphogenetic Protein)

\section{Discussion}

Spinal intradural tumor resection surgeries carry $5-18 \%$ chance of CSF-related complications, including the development of CSF fistula, pseudomeningocele, and meningitis. The complications and their respective treatments of prolonged bed rest, re-operation, and extended use of antibiotics carry significant morbidity and mortality [10]. One of the most widely used treatments for spinal CSF leak is direct suture repair of the dural tear, with a still significant failure rate of 5-9\% [1]. In patients with surgically inaccessible or irreparable dural tears, a CSF sealant such as Tisseel ${ }^{\circledR}$ or DuraSeal ${ }^{\circledR}$ may be applied, with a failure rate of $5 \%$ [11]. Another well-known treatment is the placement of the autologous fat graft over the CSF leak defect which eliminates the dead space created by the laminectomy and muscle dissection $[10,12]$.

Here we present a case of successful symptomatic CSF leak and pseudomeningocele repair with the use of BMP in a patient who underwent cervical schwannoma resection. BMPs belong to a TGF- $\beta$ superfamily of signaling molecules discovered in 1965 [7]. Their involvement is most significant in the early embryological development of mammals as well as regulation of osteogenesis [8]. In 2002, the rhBMP-2 was approved by the United States Food and Drug Administration (US FDA) for use in lumbar fusions due to its osteoinductive properties [13]. An article by Huang et al. demonstrates that rhBMP-2 induces an inflammatory state that was evident on histologic tissue sections and systemic blood samples of rats with subcutaneously implanted 
BMP [14]. It is our extrapolation that this pro-inflammatory BMP-induced response leads to quicker scarring and healing of the CSF leak defect preventing the reoccurrence of symptomatic pseudomeningocele formation.

\section{Conclusions}

In our study, none of the reported complications associated with BMP use were observed. Although BMPs are scrupulously investigated signaling molecules, more research is required to fully understand their function and use in surgery, wound healing, and tissue repair. Future studies should focus on further demonstrating the safety of BMP in the treatment of CSF leak through stronger study designs, such as a randomized controlled trial.

\section{Additional Information \\ Disclosures}

Human subjects: Consent was obtained by all participants in this study. Conflicts of interest: In compliance with the ICMJE uniform disclosure form, all authors declare the following: Payment/services info: All authors have declared that no financial support was received from any organization for the submitted work. Financial relationships: All authors have declared that they have no financial relationships at present or within the previous three years with any organizations that might have an interest in the submitted work. Other relationships: All authors have declared that there are no other relationships or activities that could appear to have influenced the submitted work.

\section{References}

1. Fang Z, Tian R, Jia YT, Xu TT, Liu Y: Treatment of cerebrospinal fluid leak after spine surgery . Chin J Traumatol. 2017, 20:81-83. 10.1016/j.cjtee.2016.12.002

2. Kaloostian PE, Kim JE, Bydon A, Sciubba DM, Wolinsky JP, Gokaslan ZL, Witham TF: Intracranial hemorrhage after spine surgery. J Neurosurg Spine. 2013, 19:370-380. 10.3171/2013.6.SPINE12863

3. Wong AP, Shih P, Smith TR, et al.: Comparison of symptomatic cerebral spinal fluid leak between patients undergoing minimally invasive versus open lumbar foraminotomy, discectomy, or laminectomy. World Neurosurg. 2014, 81:634-640. 10.1016/j.wneu.2013.11.012

4. Hawk MW, Kim KD: Review of spinal pseudomeningoceles and cerebrospinal fluid fistulas . Neurosurg Focus. 2000, 9:1-8. 10.3171/foc.2000.9.1.5

5. Rahimizadeh A, Soufiani H, Rahimizadeh S: Remote cervical pseudomeningocele following anterior cervical corpectomy and fusion: report of a case and review of the literature. Int J Spine Surg. 2016, 10:36. $10.14444 / 3036$

6. Rahman MS, Akhtar N, Jamil HM, Banik RS, Asaduzzaman SM: TGF- $\beta$ /BMP signaling and other molecular events: regulation of osteoblastogenesis and bone formation. Bone Research. 2015, 3:1. 10.1038/boneres.2015.5

7. Sheikh Z, Javaid MA, Hamdan N, Hashmi R: Bone regeneration using bone morphogenetic proteins and various biomaterial carriers. Materials. 2015, 8:1778-1816. 10.3390/ma8041778

8. Carragee EJ, Chu G, Rohatgi R, et al.: Cancer risk after use of recombinant bone morphogenetic protein-2 for spinal arthrodesis. J Bone Joint Surg Am. 2013, 95:1537-1545. 10.2106/JBJS.L.01483

9. Arnautovic KI, Kovacevic M: CSF-related complications after intradural spinal tumor surgery: utility of an autologous fat graft. Med Arch. 2016, 70:460-465. 10.5455/medarh.2016.70.460-465

10. Goodwin CR, Recinos PF, Zhou X, Yang JX, Jallo GI: Evaluation of complication rates of pediatric spinal procedures in which a polyethylene glycol sealant was used. J Neurosurg Pediatr. 2014, 13:315-318. 10.3171/2013.12.PEDS13456

11. Black P: Cerebrospinal fluid leaks following spinal or posterior fossa surgery: use of fat grafts for prevention and repair. Neurosurg Focus. 2000, 9:1. 10.3171/foc.2000.9.1.4

12. Louie PK, Hassanzadeh H, Singh K: Epidemiologic trends in the utilization, demographics, and cost of bone morphogenetic protein in spinal fusions. Curr Rev Musculoskelet Med. 2014, 7:177-181. 10.1007/s12178014-9222-2

13. Cahill KS, McCormick PC, Levi AD: A comprehensive assessment of the risk of bone morphogenetic protein use in spinal fusion surgery and postoperative cancer diagnosis. J Neurosurg Spine. 2015, 23:86-93. 10.3171/2014.10.SPINE14338

14. Huang RL, Yuan Y, Tu J, Zou GM, Li Q: Exaggerated inflammatory environment decreases BMP-2/ACSinduced ectopic bone mass in a rat model: implications for clinical use of BMP-2. Osteoarthritis Cartilage. 2014, 22:1186-96. 10.1016/j.joca.2014.06.017 